\title{
Selection of structural materials for improved Liner motion gate valves based on friction correlation method
}

\author{
J. N. Aslanov ${ }^{1}$, K. S. Mammadov ${ }^{2 *}$ and N. A. Zeynalov ${ }^{2}$ \\ Department of Oil and Gas (Mechanical Engineering), Azerbaijan State Oil and Industry University, Baku, \\ Azerbaijan ${ }^{1}$ \\ Ph.D. Student, Department of Oil and Gas (Mechanical Engineering), Azerbaijan State Oil and Industry University, \\ Baku, Azerbaijan ${ }^{2}$ \\ Received: 27-August-2021; Revised: 10-February-2022; Accepted: 14-February-2022 \\ (C)2022 J. N. Aslanov et al. This is an open access article distributed under the Creative Commons Attribution (CC BY) License, \\ which permits unrestricted use, distribution, and reproduction in any medium, provided the original work is properly cited.
}

\begin{abstract}
Technology is currently developing more than advanced, however, wear factor in the valves moving parts remain as a problem. In this paper, selection of the right materials for improved liner motion gate valves' hermetic elements is studied based on the friction correlation method. Research is carried out in wear \& tear machine for different grades of steels. A comparative analysis is done among the generated results. The hardness of new valve hermetic elements, materials was selected according to Brinell (GOST 4543). Steel $20 X$ for the first saddle, 38X2MYA alloy steel for main gate and steel $40 X$ was selected for the second saddle. It was found that the following condition must be met among the steel structures used to construct the packing element of the valve. $\mathrm{HB}_{x 1}<\mathrm{H} \mathrm{B}_{x 2}>\mathrm{H} \mathrm{B}_{x 3}$ This paper reviews the existing models used for investigating the friction and weariness in the parts of valves. Some of other methods such as finite element simulation tools were also reviewed. The main aim of this paper is to find nearly ideal material grade that can realistically be used in construction of valve elements. A comparative analysis, which includes the approaches and limitations on the related works was presented. By the end of this paper, a conclusion is drawn and suggestions aspects for future research were stated.
\end{abstract}

\section{Keywords}

Straight gate valve, Friction, Efficiency, Reliability, Longevity, Packing element, Gate, Saddle, Hermetic elements.

\section{Introduction}

One of the most needed requirements for developing technology in our today's world is to have a long life of sealant structures used in oil and gas and other industries. In turn, that makes it important to conduct more in-depth research on these structures and improve the achieved results [1]. There are several constructions included in the sealant structures and one of them is valves [2]. Nowadays, valves are being majorly used in industry. They are calculated to various pressures and being applied in different processes. The frequently malfunctioning valves are the ones being used at high pressures among the assemblies [2, 3].

\footnotetext{
*Author for correspondence

This work was supported in part by the Science Development Foundation under the President of the Republic of Azerbaijan under Grant EIF-MQM-ETS-2020-1(35)-08/04/1-M-04.
}

Although the technology is currently being developed more than advanced, the problem of friction in the working nodes of valves and the wear factor (known with its negative consequences) remains as a problem [4].

Friction occurs on the contact surfaces of valve structures, which in turn leads to failure of these pairs and premature loss of valve performance [5].

At the same time, it is known that during the operation process, the valve structures are damaged due to several effects, such as corrosion, erosion, hydro abrasive wear, and therefore it loses its reliability more premature than specified in its technical passport [6].

The main reason to hydro abrasive wear is that the product contains a lot of sand particles. These particles remain in the valve's structure due to the small gaps between the wedge and the body. When the valve is being opened or closed, the sand grains 
scratch the hermetic material during movement of stem $[2,6]$.

Due to the reason specified above, the surface is drawn along with its full width which is being ended up by creating narrow gaps between the surfaces when the valve gate is fully closed. The fluid extracted from the well leaks from these cavities inside the valve. Considering the high turbidity of the high-speed fluid, the scratches on these surfaces quickly turn into large washes, which, if detected in time, can be reused by repairing its junction details However, this is not always possible, and, in most cases, it is difficult to determine such kind of washes during operation as well as other similar situations, and thus the trunk becomes irreversible In case valve is not fully closed or opened, then the product being extracted from wells flush the part of valve in front $[7,8]$.

As an addition to the above-mentioned statements, there are also a lot of issues being faced with the valve seating in current industry which need future exploration and relevant study to be carried out.

One of the main aims in current article is to increase the longevity of valves by keeping the wear factor to a minimum in the sealing surfaces which are in regular contact with each other such as the saddles and gates. As it is defined, if we minimize the wear factor in any design structure, then we will increase the longevity of that equipment many times over. Our research showed that the choice of the strength of valve technical parts should be based on a relevant regularity $[9,10]$. A comparative analysis of different construction shows that the choice of hardness of sealing elements' materials has a direct impact on the longevity of the structure.

Ensuring the performance of valve details basing on the criteria of strength and rigidity referenced to their technical data, allows to guarantee workability of valve on the criteria of tightness, controllability, and others. The hardness of the details depends on their durability, as well as their resistance to wearness. Therefore, ensuring the efficiency of these criteria allows to ensure the required reliability of the valve.

As a result of our research at NEFTGAZMASH OJSC, it became clear that when the hardness of the pressurized parts exceeds the hardness of the pressed part, the working surfaces - the second working surface - are perforated [10,11]. Different types of ZMS and ZMAD valves have been studied and it has been found that the current problem reduces the longevity of the valves [12].

The structure of the construction has also a great importance in this regard, as structural part details must be determined based on the principle of equal distribution of pressure on the contact surfaces. And in this designation, the choice of parts hardness has to be referenced the basis of peculiar research [7, 13]. For this purpose, the research considered for the selection of hermetic elements' hardness details of the shuttering node and the installation of constructive details based on this selection [14].

The objective of this paper is to find nearly ideal material grade that can realistically be used in construction of valve elements. The mechanical properties such as hardness, friction, distortion of different materials was measured. The extensive literature about approach of different authors to the known issues was discussed in section 2. The materials and methods employed in preparing and testing the steel materials were presented in section 3 . Whereas section 4 covers the experimental results, hardness factors of different kind of steel materials. The comparative analysis of the obtained experimental results of different steel materials was discussed in detail in section 5. Conclusion and future work covered in section 6 .

\section{Literature review}

The problem that is being highlighted in current article has been reviewed by several authors at different years, and some feasible solutions proposed as well as implemented during the timeframes.

In 2012 Cohn [15] conducted his comprehensive research to have the characteristics and performance of the valves being used in industry. He attempted to parameterize the torque by using the available data which was taken from the previous experiments carried out on the same subject and looked at the coefficient by basing on the thickness to diameter ratio for numerous valve geometries, most of which were symmetrical.

Thus, in 2015 there is a different solution provided by Aslanov and Mammadov [16] in the conference held in Canada which was dedicated to increase the improved plug valve's efficiency by modifying its construction. Several calculations run by using the applied mechanical engineering methods. As a result, construction of plug valve can be improved by resolution of wrenching force on working pressure, 
which happens on tightened contact area of packing nodes of it. A new formula suggested to identify the relevant surface pressures which is being occurred over the contact surfaces. It provides tightening of packing node of plug valve and the permissible relative pressure.

In 2019 He et al. [17] discussed about the finite element calculation of the materials being used for manufacturing of valves and its relevant parts. Finite element analysis (FEA) was also done in those parts which are mostly subject to wear \& tear- packing elements. The FEA results showed that the characteristics of the valve and it is longevity is mostly dependent on materials being used for fabrication [18].

In 2019 Nuraddin et al. [18] applied the fuzzy logic for the different materials to predict the efficiency changes of improved valve constructions during the statical data-based exploitation. A varied range of the application in current industry to determine the efficiency of valves is currently being applied. It assists to determine what the worst-case failure scenario of possible failures could be caused in the flow lines by loss of valves.

In 2020 Titenko et al. [8] discussed about the materials under the influence of temperature and their mechanical stresses. The discussion was mainly based on the $\mathrm{Cu}-\mathrm{Al}-\mathrm{Mn}$. Afterwards there was a transformation of the information by using the method of variations for the constructions of the valve manufacturing principles. The article published in Materials Science Applied Nanoscience [8, 19].

In 2021 Aslanov et al. [1] discussed about the materials used for valves which are mainly consisted of the rubbers, rubber type of seals. The several matrixes of the rubber seals have been constructed and reviewed in various conditions. The finite element of the rubbers identified. This information provided a range of several variables for the application of rubber in current constructions used in industry [19].

In 2021 Chen et al. [20] reviewed the tribological analysis of picosecond laser partially textured thrust bearings with circular machined grooves. The authors used the same machine for tribological analysis, and then they transferred results to a comparison model. In the other hand, the authors suggested to use a twodimensional analytical model based on the Reynolds equation considering mass conservation cavitation is proposed to investigate the performance of partially textured thrust bearings with circular grooves. Tribological experiments carried out on an MMW-1 tribological rig. The average friction coefficient and friction reduction ratio applied to analyses tribological performance of partially textured thrust bearings. Through a comparative analysis, the optimal geometrical values obtained from experimental results were in good agreement with the theoretical analysis, especially at high rotation speeds and a low load condition.

These reviewed articles have been contingent on new valve models, which are only valid for no disturbances by other particles during the movement of fluid in the valve, such that they are restricted to ideal operating conditions. Therefore, the aim of this article is to find nearly ideal material grade that can realistically be used in construction of valve elements and compare their performances in different conditions by using various methods.

\section{Methods}

3.1Selection of structural materials of improved liner motion gate valves through the experiments

The main working part of the valve is its hermetic element. Most failures and rejections are observed in these parts considering that they always work under pressure and meanwhile provide fully sealing of the valve throughout their lifetime. The hermetic element main joint is its pairs of gate/wedge and saddle/seat ring. One of the main reasons for failure of the gate saddle pair is the change in shape of parts of the sealing element due to unequal distribution of relative pressure through its sealing surface. Additionally, lack of pairs matching as well as ire-reconciling at the initial wearing period led to have a failure in the hermetic elements. As a result of product compression (which being extracted from wells) to the annular working part of saddle construction under some defined pressure, the round part of the hermetic element being bent along the radius (diameter) of the circular which freely sits in pair of rings. Consequently, the principal of pressure's equal distribution is being ignored over the contact phases of the gate-saddle pairs $[21,22]$.

Such problems, reduce the unit's efficiency and accelerates rapid failures because of the aggressiveness of liquid and gas passing through the valve during operation. The impact of abrasive and mechanical particles in the unit, as well as the effects of various corrosion processes because of contact 
between pairs consider another major factor for loss of efficiency and reason for possible failures. Unequal distribution of relative pressure on working surface causes it to be worn during forward and backward movement of hermetic element when the valve is opened and closed. It also destroys the metalto-metal contact surfaces during the movement. Given that the product extracted from well contains mainly abrasive particles, it is inevitable that this, in turn, will reduce the performance of the pair of gate and saddle, thus, after some time, will make it unusable. Improvement of the closing units' packing elements is being carried out mainly in several ways.

So far, different solutions for such issues considered, various assumptions, opinions and methods put forward for improvement [23].

Experiments showed that one of the main causes of wear and tear is the selection of materials in valve structure. As referenced earlier, the phenomenon of friction, corrosion occurs mainly during metal-tometal friction in gate-saddle pairs [24, 25]. Therefore, the current research paper is also devoted to study of friction-corrosion process that occurs during the movement of different steel structures onto each other [26-29].

Taking above referenced points into consideration, it could be concluded that main wear and friction occurs over gate-saddle pairs in valve structures. In order to carry out the detailed analysis, the samples prepared from following steels: ST 20, ST 20X ST 40 and ST 40X and their wear and friction processes studied. The experiment carried out in the laboratory of Department of Oil and Gas Equipment of Azerbaijan State Oil and Industry University. To carry out the experiment, MKS-10 MMW-1vertical universal friction machine used which was manufactured by Jinan Fangyuan Testing Machine CO. Ltd, shown in Figure 1. As it is known, these materials behave differently depending on the structural changes. Wearing of different shaped material surfaces which are in contact with each other is also different, despite the same materials used to prepare them. It depends on impact force's contact angle [30-34].

To carry out the experiment, a cylindrical steel rod sample and a circular steel sample was prepared as shown in Figure 2. Temperature, pressure, and time are considered as the main parameters for the experiment to be carried out.
A circular sample was prepared to attach the equipment to the "stationary seat" and it was placed on the sample table of the equipment with a small clamp. The cylindrical rod is attached to the upper rotating knot of equipment. Rotating knot is rotated on a stationary seat by applying a load to the equipment on a pre-prepared schedule at variable time intervals. The phenomenon of friction-corrosion that occurs during the movement on metal-metal (ST 20-ST20; ST 20X-ST 20X; ST40 -ST40; ST40XST40X) was considered and appropriate graphs were obtained. Later, the results in graphs compared to each other based on the hardness factors. The results were also compared to another steel structure which of the three constructed packing element of the valve [35-37]. Figure 1 shows the equipment used for the testing, and Figure 2 shows the prepared samples in order to conduct the test.

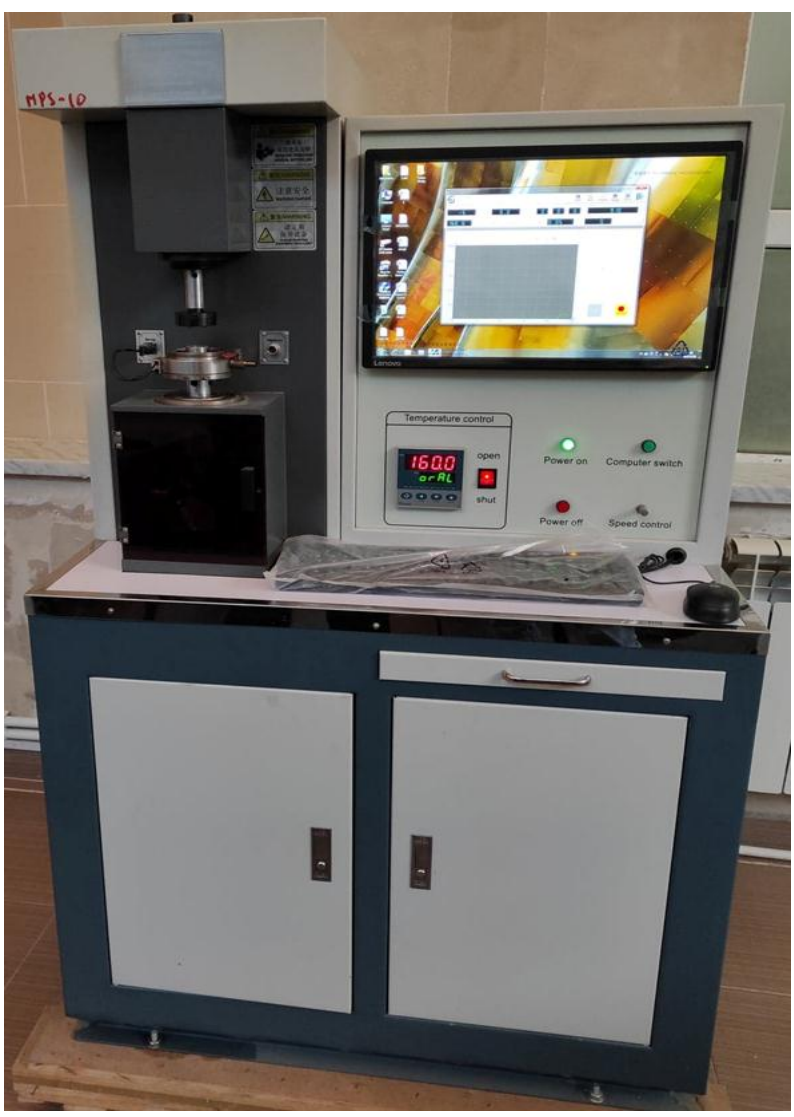

Figure 1 Jinan Fangyuan testing machine CO. Ltd, MKS-10 MMW-1 vertical-universal wearing machine 


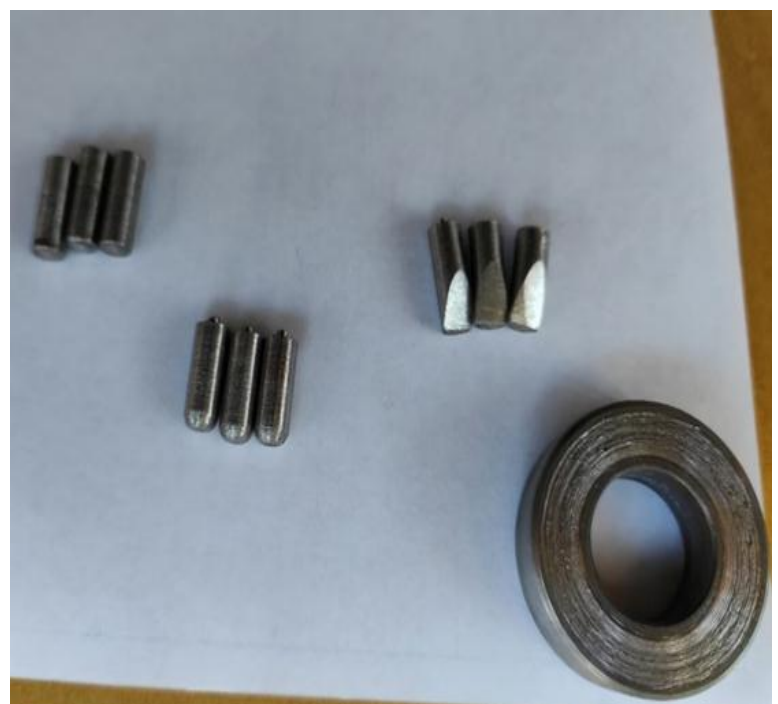

Figure 2 Steel samples prepared for testing

The experimental conditions include the loads till 150 $\mathrm{N}$ with contact pressures of $0.00-1 \mathrm{MPa}$, rotation speeds of 200-600 r/min, room temperature (RT), and test durations of 200-250 s. Each sample is tested at rotation speeds of 200-600 r/min (with an interval of $100 \mathrm{r} / \mathrm{min}$ ). The data at each speed are collected after the stabilization of the friction coefficient.

\subsection{Selection of structural materials of improved} liner motion gate valves by using formulas

The main purpose of this article is dedicated to improving longevity and workability of valve by applying variation method of various materials with different hardness. The relative pressure unequal distribution in hermetic element of a valve is an important reason which causes the loss of workability. Obtained results of the experiment will be a guidance for modifying hermetic elements and re-construct a seat for these elements inside of a valve. Therefore, the hardness of the different materials, verified $[38,39]$.

In summary, basing on the literature reviews as well as experiments conducted, it can be said that possibility to reach the aforementioned purpose could be possible by evaluating several options which can be listed as per following:

- Loss in force

- Change the construction of hermetic elements

- Change the construction (or re-construct) of seats according to geometric parameters of the valve improved hermetic elements.
- Chose the materials in different hardness which can be smoothly squeezing each other where it is necessary

A hermetic element of valves consists of both rubber and metal rectangle rings. However, these rings provide the compactness when fitting onto each other. Rubber seal is subjected to cutting tension due to uneven distribution of relative pressure (inside of the rubber hermetic element) which causes hermetic compactness by squeezing the packing elements to each other. Eliminating mentioned tension will ensure longevity of hermetic element. It is recommended to separate the rectangular hermetic element of valve into two parts by delimiting to triangular and trapezoidal flatness elements to sort out the problem.

Trapezoidal element has got a centerpiece running considering triangular element is the first defined element during the influence of working pressure. Therefore, the triangular element will take the initial tension on itself, whereas trapezoidal element remains with less tension in comparison with triangular element. Thus, triangular and trapezoidal elements are compressed onto each other over contact surfaces. Consequently, in hermetic elements' seats equal distribution of relative pressure is mostly ensured [40-46].

Based on the experiment on different steel structures, choosing of materials will be mainly dependent on application of valves in which industry and follow the requirements of relevant standards.

A part of the above referenced points, below mathematical formula would need to be met during the construction of a valve packing element. Following the case study reviewed to get the results.

The gate is compressed to the second saddle at the discharge line with a higher force. In this case, the stiffness of the cylindrical plate loaded with an evenly distributed load in the central axis zone of the saddle and resting freely on the contour will be as per Equation 1:

$D=\frac{E h^{3}}{12(1-\mu)}$

here,

D- stiffness of the cylindrical plate

E - elasticity module

$\mathrm{h}$ - thickness of the gate

$\mu$ - Poisson's ratio 
According to the thick slab's theory, in which the gate is partly related to the ratio of its geometric dimensions, its maximum deflection is as per Equation 2:

$w=w_{c}^{\prime} \cdot\left[1+0,7\left(\frac{2 h}{D_{0}}\right)^{2}\right]$

Where,

$\mathrm{W}$ - maximum distortion (centre)

$w_{c}^{\prime}$-maximum distortion for cylindrical plate loaded with an evenly distributed load in the central axis zone of the saddle and resting freely on the contour $D_{0}$ - the diameter of the circle contour on which the gate compresses

$D_{x j}$-external diameter of the contact surfaces bet between saddle and gate in discharge

In Equation 3 the allowable deflection of the gate is determined to provide that sealing parts of distortion resistance are ensured.

$[w]=\frac{2 w_{c}^{\prime}}{D_{x j}} \cdot \sqrt{\frac{8 \theta_{c o m p}}{\pi q_{m}}}$

$[w]$-permissible maximum distortion $q_{m}$-relative contact tension

$\theta_{\text {comp }}$-force squeezes the gate at the discharge

The above referenced formula is concluding the maximum permissible distortion for the different materials of the gate and saddle. It is determined that the results obtained from mathematical calculations by the referenced formula would need to be experimentally proved.

The novelty of the approach is that the selection of equipment parts is based on the friction correlation method. This method is based on the individual determination of strength of equipment details. The friction behavior during the surface contact of different parts at various hardness is checked. Processing of the results obtained allows us to select the details of the equipment based on the friction correlation of the materials, resulting in reduced wear of the contact parts. This increases the longevity of the working surface of the parts accordingly.

As referenced above, the different steel materials were chosen for reference to continue with testing. It can be summarized as per following:

Steel 20X (as per GOST 7809) consists of the following main chemical composites (Table 1):

160
Table 1 Chemical composites Steel 20X (as per GOST 7809)

\begin{tabular}{llllllll}
\hline $\mathbf{C}$ & $\mathbf{S i}$ & $\mathbf{M n}$ & $\mathbf{P}$ & $\mathbf{S}$ & $\mathbf{C r}$ & $\mathbf{C u}$ & $\mathbf{N i}$ \\
\hline 0.17 & 0.17 & 0.35 & $\leq$ & $\leq$ & $\leq$ & $\leq$ & $\leq$ \\
- & - & - & 0.03 & 0.04 & 0.2 & 0.3 & 0.3 \\
0.24 & 0.37 & 0.65 & 5 & 0 & 5 & 0 & 0 \\
\hline
\end{tabular}

Steel 40 is a high-quality carbon steel and is widely used in construction and engineering. As per state standard of the Soviet Union (GOST) 1050-88 and GOST 7809, its chemical composites are consisted of the following items shown in Table 2.

Table 2 Chemical composites steel 40 (as per GOST 7809)

\begin{tabular}{llllllll}
\hline $\mathbf{C}$ & $\mathbf{S i}$ & $\mathbf{M n}$ & $\mathbf{P}$ & $\mathbf{S}$ & $\mathbf{C r}$ & $\mathbf{C u}$ & $\mathbf{N i}$ \\
\hline 0.37 & 0.17 & 0.50 & $\leq$ & $\leq$ & $\leq$ & $\leq$ & $\leq$ \\
- & - & - & 0.03 & 0.04 & 0.2 & 0.3 & 0.3 \\
0.45 & 0.37 & 0.80 & 5 & 0 & 5 & 0 & 0 \\
\hline
\end{tabular}

\section{Result}

Figure 3 determines the movement of 2 steel samples onto each other, and the relevant graphs show the wear changes over the period (sec) dependance on force (N) applied and called "Load Time Curve". Here, both materials are the same ST 20X - ST 20X. A circular sample was prepared by ST 20X to attach the equipment to the "stationary seat", and it was placed on the sample table of the equipment with a small clamp. The cylindrical rod, which was also prepared by ST 20X attached to the upper rotating knot of the equipment. The rotating knot was rotated on a stationary seat by applying a load to the equipment on a pre-prepared schedule at variable time intervals.

As it can be noticed the wear increases at the beginning to a level and then starts to decrease over the period for the same steel materials while moving onto each other. Applied load varied during the time change and consequently the wearing factor changed accordingly.

Figure 4 determines the movement of 2 steel samples onto each other, and the relevant graphs show the wear changes over the period (sec) dependance on the force $(\mathrm{N})$ applied and called "Load Time Curve". Here, the materials chosen to differ from each other, such as the one is ST 20X whereas another one is ST $40 \mathrm{X}$.

A circular sample was prepared by ST 20X to attach the equipment to the "stationary seat", and it was 
placed on the sample table of the equipment with a small clamp. The cylindrical rod, which was prepared by ST $40 \mathrm{X}$ attached to the upper rotating knot of the equipment. The rotating knot was rotated on a stationary seat by applying a load to the equipment on a pre-prepared schedule at variable time intervals.

As it can be noticed the wear increases at the beginning to a higher level and almost reaches its maximum which is the time when two different metal surfaces contact with each other. After a while, the decrease of the wearing observed during the normalization of ST $40 \mathrm{X}$ movement onto ST 20X. The increase of the force lead to have the increment of wearing after certain time and it reaches a level of wearing again. Applied load is varied during the time and consequently the wearing factor changed accordingly.
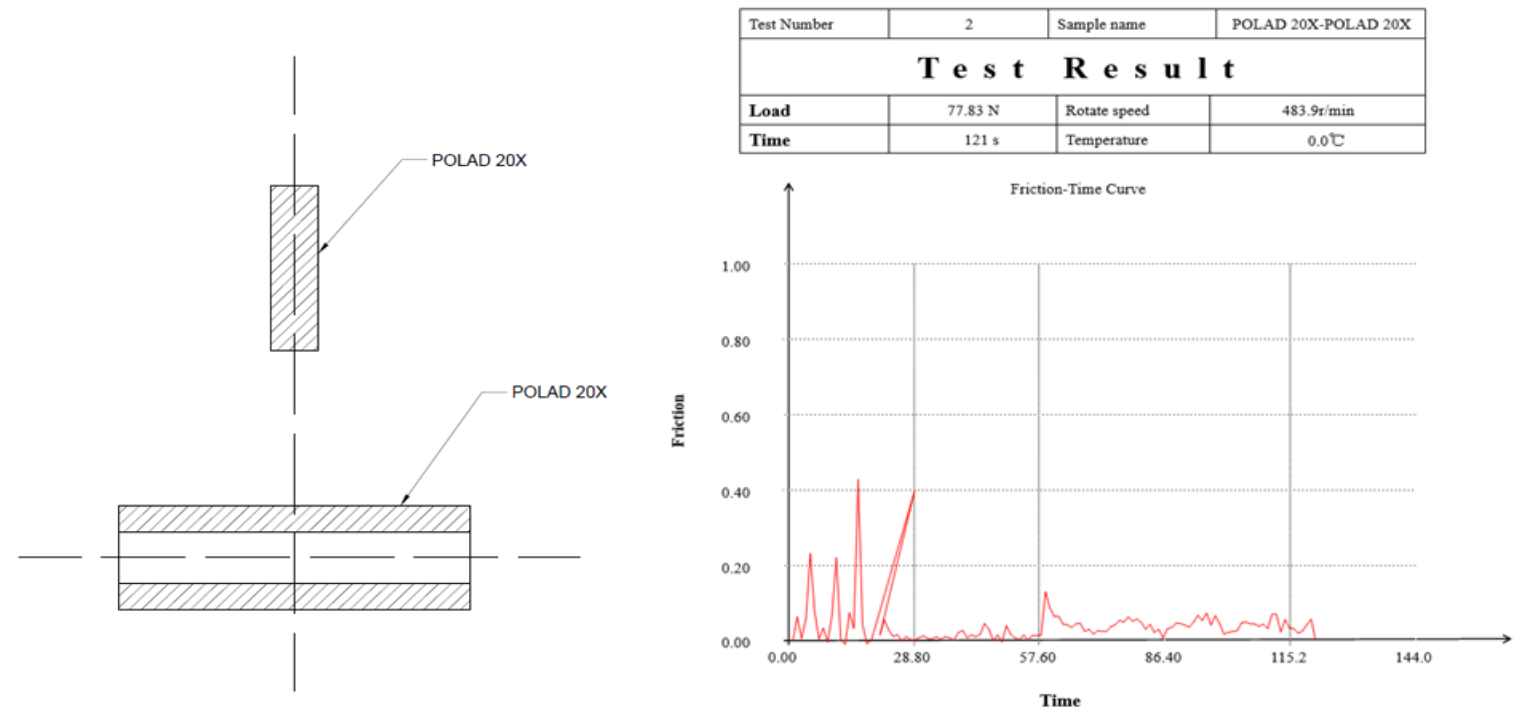

Figure 3 Processing of the experiment in Example 1
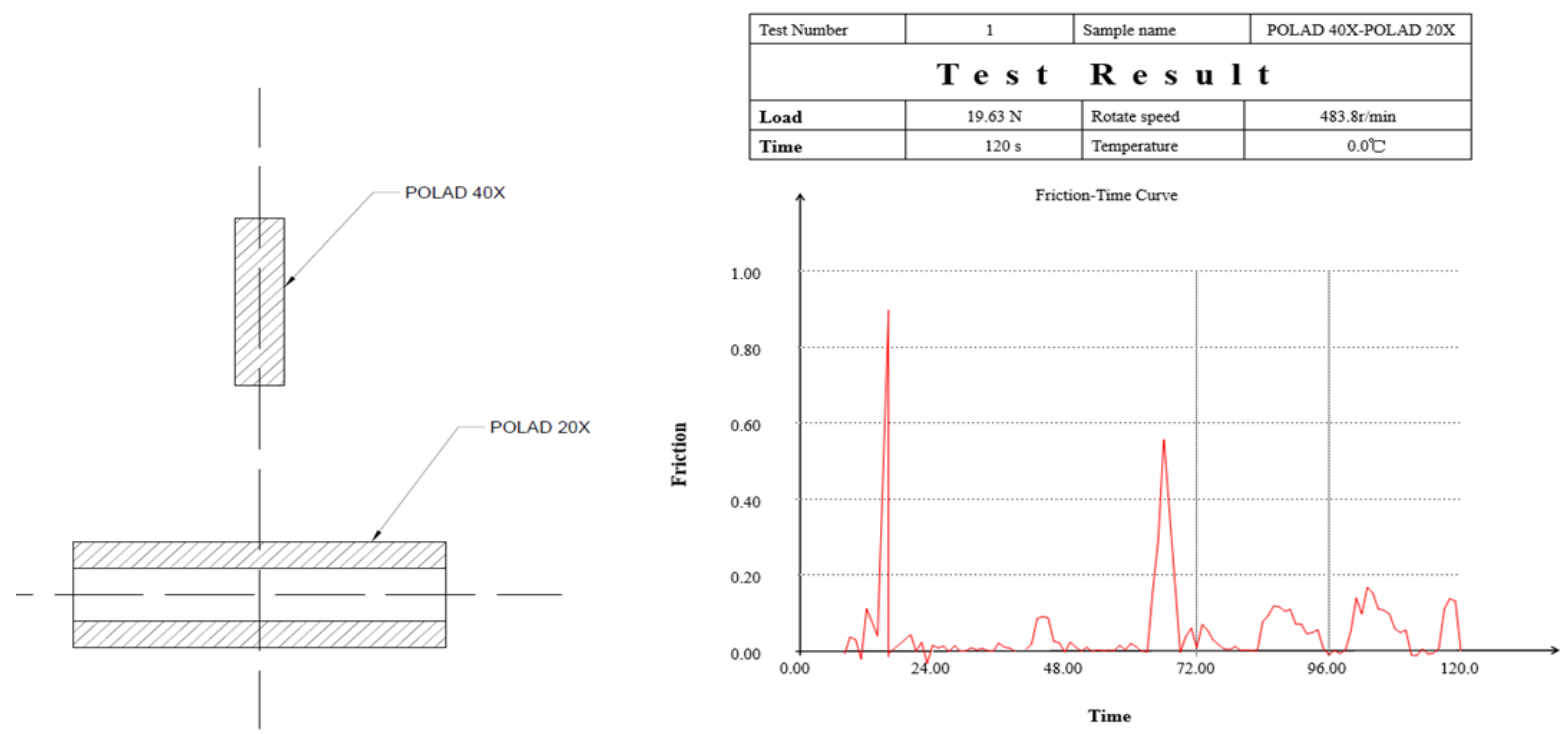

Figure 4 Processing of the experiment on example 2 
Figure 5 determines the movement of two steel samples onto each other, and the relevant graphs show the wear changes over the period (sec) dependance on the force $(\mathrm{N})$ applied and called "Load Time Curve". Here, the materials chosen to differ from each other, such as the one is ST 40X whereas another one is ST 20X.

A circular sample was prepared by ST $40 \mathrm{X}$ to attach the equipment to the "stationary seat", and it was placed on the sample table of the equipment with a small clamp. The cylindrical rod, which was prepared by ST $20 \mathrm{X}$ attached to the upper rotating knot of the equipment. The rotating knot was rotated on a stationary seat by applying a load to the equipment on a pre-prepared schedule at variable time intervals.

As it can be noticed the wear is not considerably higher at the beginning, however it reaches to a certain level of increase when two different metal surfaces contacted with each other and started to move for a while which led a continuous wearing. After a while, the decrease of the wearing observed during the normalization of ST 20X movement onto ST $40 X$. The increase of the force lead to have the decrease of wearing after a certain time as it reaches a level of "normal wearing" due to contacted surfaces smooth movement to each other. Applied load is varied during the time and consequently the wearing factor changed accordingly.

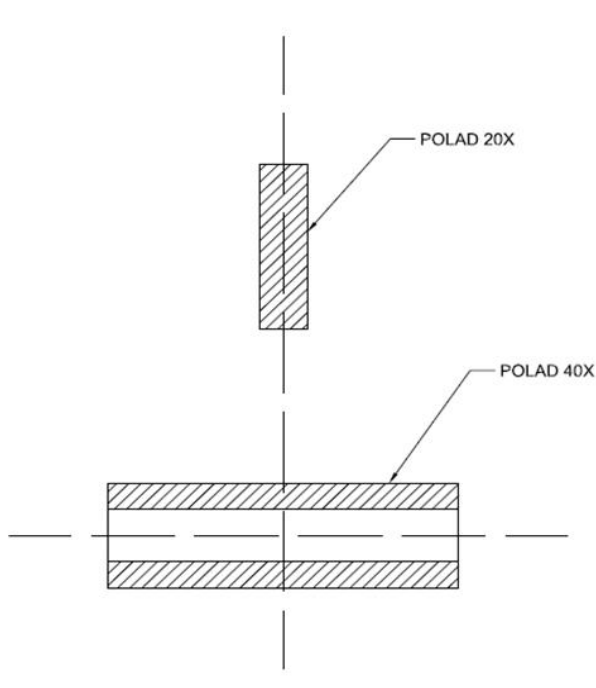

Figure 5 Processing of the experiment on example 3

Figure 6 determines the movement of two steel samples onto each other, and the relevant graphs show the wear changes over the period (sec) dependance on the force $(\mathrm{N})$ applied and called "Load Time Curve". Here, the materials chosen to be the same ST 40X - ST 40X.

A circular sample was prepared by ST $40 \mathrm{X}$ to attach the equipment to the "stationary seat", and it was placed on the sample table of the equipment with a small clamp. The cylindrical rod, which was prepared by ST 40X attached to the upper rotating knot of the equipment. The rotating knot was rotated on a stationary seat by applying a load to the equipment on a pre-prepared schedule at variable time intervals.
As it can be noticed the wear is not that dramatically high at the beginning prior to having the surfaces contacted with each other, however it reaches to a certain level of increase when two metal surfaces contacted with each other and started to move for a while which led a continuous wearing. After a while, the decrease of the wearing is observed during the normalization of ST 40X movement onto ST $40 \mathrm{X}$ despite it is still high enough for the acceptance level of the wearing. The increase of the force lead to have the increase of wearing after certain time and it never reaches a level of "normal wearing" considering the hardness of the chosen steel materials. Applied load is varied during the time and consequently the wearing factor changed accordingly. 

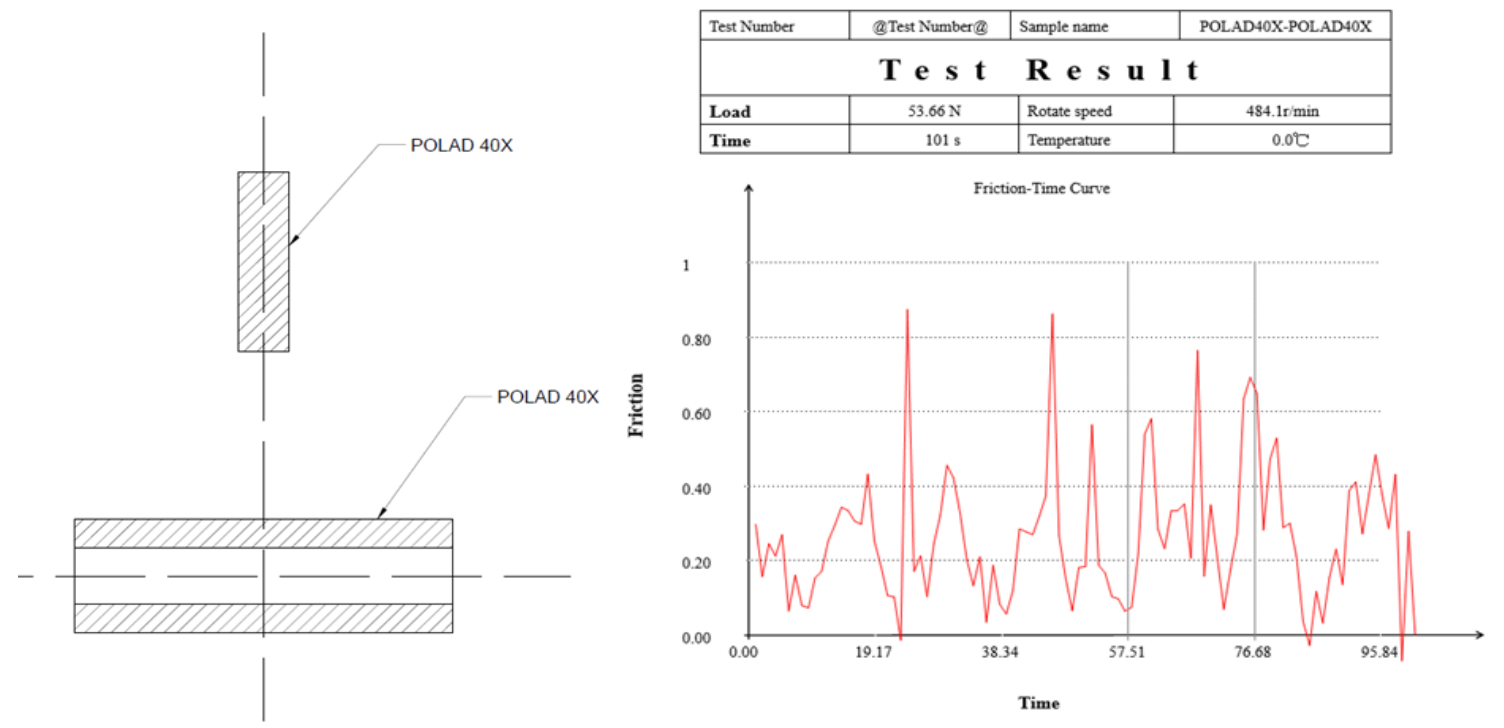

Figure 6 Processing of the experiment on example 4

\section{Discussion}

5.1Comparative analysis of the obtained experimental results

Movement of two steel samples onto each other by taking the weariness into account is mostly dependent on the correct choice of the materials observed from the above referenced tables and the sample graphs. The shape of samples also led to have the differentiation in the weariness process considering the increase of wear is mainly dependent on the angle of moving parts onto the stationary seat. However, considering the current samples all are made as cylindrical, the case referenced above is ignored in our case.

The compared samples in the machine are considered as ST 20, ST 20X, ST 40, ST 40X. As it can be noticed the wear process is mainly based on the change of materials and movement of parts onto each other based on their hardness.

While having the ST20X moves onto ST 20X, the wear increases at the beginning to a level and then start to decrease over the period. Whereas the ST40X moves on ST 20X the wear soars at the beginning to a higher level and almost reaches its maximum which is the time when two different metal surfaces contact with each other. After a while, the decline of the wearing is observed during the normalization of ST 40X movement onto ST 20X. The increase of the force lead to have the increment of wearing after certain time and it reaches a level of wearing again.
The wear is not considerably higher at the beginning during movement of the ST 20X over the ST 40X. However, it reaches to a certain level of grow when metal surfaces contacted with each other and started to move for a while which led a continuous wearing. After a while, the decrease of wearing is observed during normalization of ST 20X movement onto ST 40X. The increase of force led to have decreased of wearing after a certain time as it reached a level of "normal wearing" due to contacted surface smooth movement to each other. This cannot be observed at the same while ST 40X moves on ST 40X. During the movement of the same $40 \mathrm{X}$ steel materials onto each other, the wear is not that tremendously high at the beginning prior to having the surfaces contacted with each other. It reaches to a certain level of increase when two metal surfaces contacted with each other and started to move for a while which led a continuous wearing. After a while, the decrease of the wearing is observed during the normalization of ST 40X movement onto ST 40X. It is still high enough for the acceptable level of the wearing. The increase of the force lead to have increase of wearing after certain time and it never reaches a level of "normal wearing" considering the hardness of chosen steel materials.

Putting all aforementioned in a nutshell, analysis of the graphs of the experiments shows that the speed of wear in friction increases while the hardness of the steel rod sample increases. Hardness of the squeezing rod stiffness is lesser than that of the compressed corresponds to the lowest value of the frictional wear intensity in the experimental specimens. As an 
overall result, correlation of friction process for the conditions where ST 20X considered as squeezing and ST 40X considered as compressed samples is fully consistent. Thus, material hardness for the gate to be chosen much harder than the material hardness for saddle in improved valves. However, such a margin should not be dramatically different. To conclude, the material of the valve hermetic element must be selected correctly. The process of installing it in the slot must be provided in an appropriate manner and the shape of the material must be designed as required. This design should be selected based on the friction correlation method, depending on the construction of valve's improvement. Thus, the distribution of the structural materials in the hermetic element of the improved valve construction which we proposed must be selected in accordance with the following law:

$H B_{x 1}<H B_{x 2}>H B_{x 3}$

Equation (4) - indicates the correlation of friction at the hermetic nodes of the proposed valve construction.

By choosing the correct material, we ensure an even pressure distribution generated on the surfaces during the contact process. As a result, the material is being considered as fully compatible for the pressure equipment. And this result eliminates the possibility of having cracks and penetrations over surfaces.

Hardness of new valve structure's sealing details selected according to Brinell (based on GOST 4543). It was noted that the first sealing element (for saddle) was selected as steel 20X, the second detail (which is for main gate) was selected as 38X2MYA alloy steel, the third sealing element (for saddle) was selected as steel 40X.It was found that the following condition (Equation 5) must be met among the steel structures being used to construct the packing element of the valve.

$H B_{x 1}<H B_{x 2}>H B_{x 3}$

During the study, it was found that the hardness of first saddle should be $207 \mathrm{HB}$ per Brinell, the hardness of the gate should be $250 \mathrm{HB}$ per Brinell, and hardness of the second saddle should be 197 HB per Brinell. Substituting the results of hardness into the above equation, following dependence will be obtained (Equation 6):

$207 H B<250 H B>197 H B$
In this case, the condition of Equation 6 considered as met and this is in line with the experiment run for the different steel materials. A complete list of abbreviations is shown in Appendix I.

\subsection{Limitations of experimental study}

The result of the current study can be applied to constructive structures where frictional erosion and weariness occur on their surfaces. By minimizing the frictional wearing, longevity and reliability of the different working constructions will be ensured. In this work, analysis is carried out under ideal conditions and results mostly focused on the changeable friction points. However, the actual scenario of wear is also dependent on some other factors which cannot be simulated through the wear $\&$ tear machine.

\section{Conclusion and future work}

A comparative analysis of the different grade steels used in the improved valve structures revealed that one of the ways to increase the efficiency and reliability of the valve is to select the materials of its main joints based on friction correlation.

A comparison of different grades of steels used in the valve's hermetic element constructions showed that the main condition for minimizing the wear of the valve's main nodes between the pair of gate and saddles is that the hardness of its parts to be chosen higher than the other.

The hardness selection of the new valve packing elements' details is carried out based on regularities, specified in the formula $H B_{x_{1}}<H B_{x 2}>H B_{x 3}$. Thus, the hardness selection of valve details will increase the packing elements.

Selecting the hardness of surfaces by proposed method will prevent the working surfaces from cracks and penetration. It was revealed that the hardness of the first saddle should be $207 \mathrm{HB}$ per Brinell, the hardness of the gate should be $250 \mathrm{HB}$ per Brinell, and the hardness of the second saddle should be 197 HB per Brinell. As a future work following points to be considered: Loss in force to be achieved to increase the efficiency of the valves being used in industry. Change the construction of hermetic elements or re-construct the seat, according to geometric parameters of the improved hermetic elements.

\section{Acknowledgment}

None. 


\section{Conflicts of interest}

The authors have no conflicts of interest to declare.

\section{Authors contribution statement}

J.N. Aslanov: Conceptualization, investigation, data curation, writing - original draft. K. S. Mammadov: Data collection, conceptualization, writing - original draft, writing - review and editing, draft manuscript preparation analysis and interpretation of results. N.A. Zeynalov: Study conception, data collection, supervision to the actual laboratory tests, investigation on challenges.

\section{References}

[1] Aslanov JN, Abasova SM, Huseynli ZS. The management of characteristics of the new two-layer rubber matrix seals. EUREKA: Physics and Engineering. 2020; 5:60-8.

[2] Albaina I, Arregui FJ, Bidaguren-alday C, Bidaguren I. Influence of butterfly and gate valves upstream large water meters. Water. 2020; 12(9):1-24.

[3] Zic E, Banko P, Lesnik L. Hydraulic analysis of gate valve using computational fluid dynamics (CFD). Scientific Review Engineering and Environmental Sciences. 2020; 29(3):275-88.

[4] Capodaglio EM. Comparison between the CR10 Borg's scale and the VAS (visual analogue scale) during an arm-cranking exercise. Journal of Occupational Rehabilitation. 2001; 11(2):69-74.

[5] Lin Z, Sun X, Yu T, Zhang Y, Li Y, Zhu Z. Gas-solid two-phase flow and erosion calculation of gate valve based on the CFD-DEM model. Powder Technology. 2020; 366:395-407.

[6] Michalska-pozoga I, Jakubowski M. CFD analysis of the flow of a polymeric material inside the doublecone plasticization-homogenization zone of the screwdisc extruder. Przemysl Chemiczny. 2015; 94(12):2105-11.

[7] Vahidov MA, Karimov OM, Eyvazova ZE. Oil and Gas equipment, 2008.

[8] Titenko A, Demchenko L, Kozlova L, Babanli M, Ren TZ, Titenko Y. Deformational behavior of $\mathrm{Cu}-\mathrm{Al}-\mathrm{Mn}$ alloys under the influence of temperature and mechanical stress. Applied Nanoscience. 2020; 10(8):3097-101.

[9] Lin Z, Ma G, Cui B, Li Y, Zhu Z, Tong N. Influence of flashboard location on flow resistance properties and internal features of gate valve under the variable condition. Journal of Natural Gas Science and Engineering. 2016; 33:108-17.

[10] Mamedov VT, Mamedov GA, Aslanov JN. Stressstrain state of sealing rubber membranes at large deformations. Journal of Applied Mechanics and Technical Physics. 2020; 61(2):286-91.

[11] Harp SR, Salant RF. Inter-asperity cavitation and global cavitation in seals: an average flow analysis. Tribology International. 2002; 35(2):113-21.

[12] Babanlı MB, Mamedov GA, Mammadov VT, Aslanov JN. İmpact of thermoelastik deformation on work of rotatıng preventers sealıng. In science and education: materials of the x11 international research and practice conference. 2016.

[13] Srivastava S, Shet K, Kulkarni S. A comparative study of two methodologies for nonlinear finite element analysis of knife edge gate valve sleeve. International Journal of Mechanical Engineering and Technology. 2015; 6(12):81-90.

[14] Kyzy SAB, Nuraddin AJ, Kyzy HZS. Diagnostics of high pressure oil equipment. International scientific and practical conference 2021 (pp. 65-9).

[15] https://digitalcommons.usu.edu/cgi/viewcontent.cgi?re ferer $=\&$ httpsredir $=1 \&$ article $=2454 \&$ context $=$ etd . Accessed 20 November 2021.

[16] Aslanov CN, Mammadov KH. İncreasing improved plug valve's efficiency. Science, Technology and Higher Education. 2015.

[17] He X, Zhang C, Tian D. Strength analysis and structure optimization of gate valve body based on finite element software. In E3S web of conferences 2019 (pp. 1-6). EDP Sciences.

[18] Nuraddin AJ, Baxman SA, Abulfas HI. Model design for predicting the efficiency of improved valve constructions during statistical data based exploitation. IFAC-PapersOnLine. 2019; 52(25):547-50.

[19] Ibrahim H , Camaladdin H. Simulation of kinetic curves of thermo-oxidative destruction of prolimers using differential equations of fractional order. ETM Equipment, Technologies, Materials. 2021:52-62.

[20] Chen T, Ji J, Fu Y, Tian P, Zhou J, Yang X. Tribological analysis of picosecond laser partially textured thrust bearings with circular grooves machined: theory and experiment. Proceedings of the Institution of Mechanical Engineers, Part J: Journal of Engineering Tribology. 2022; 236(1):105-22.

[21] US Department of Energy. DOE fundamentals handbook: mechanical science. 2016.

[22] Magazine of Toficgo, uploads 04/VG_RU-nouvelleadresse, 2015.

[23] Addy AL, Morris MJ, Dutton JC. An investigation of compressible flow characteristics of butterfly valves. Journal of Fluids Engineering, Transactions of the ASME.1985; 107(4):512-7.

[24] Eom K. Performance of butterfly valves as a flow controller. Journal of Fluids Engineering. 1988; 110(1): 16-19.

[25] Kimura T, Tanaka T, Fujimoto K, Ogawa K. Hydrodynamic characteristics of a butterfly valveprediction of pressure loss characteristics. ISA Transactions. 1995; 34(4):319-26.

[26] Lin F, Schohl GA. CFD prediction and validation of butterfly valve hydrodynamic forces. In critical transitions in water and environmental resources management 2004 (pp. 1-8).

[27] Song X, Wang L, Park Y. Fluid and structural analysis of large butterfly valve. In AIP conference proceedings 2008 (pp. 311-4). American Institute of Physics.

[28] Guan SX, Park YC. Numerical analysis of butterfly valve-prediction of flow coefficient and hydrodynamic torque coefficient. In proceedings of the world 
J.N. Aslanov et al.

congress on engineering and computer science 2007 (pp. 24-6).

[29] Chaiworapuek W, Champagne JY, El HEM, Kittichaikan C. An investigation of the water flow past the butterfly valve. In AIP conference proceedings 2010 (pp. 249-62). American Institute of Physics.

[30] https://www.plm.automation.siemens.com/global/en/p roducts/simcenter/STAR-CCM.html. Accessed 23 November 2021.

[31] Butterfly valves-torque, head loss, and cavitation analysis: M49. American Water Works Association; 2001.

[32] Yunus A, Çengel, Cimbala JM. Fluid mechanics: fundamentals and applications. McGraw-Hill Higher Education; 2010.

[33] Coleman HW, Steele WG. Experimentation, validation, and uncertainty analysis for engineers. John Wiley \& Sons; 2018.

[34] Munson BR, Okiishi TH, Huebsch WW, Rothmayer AP. Fluid mechanics. Singapore: Wiley; 2013.

[35] Patil PB, Gambhire VR. Structural analysis of gate valve body using FEA. International Journal of Engineering Research \& Technology. 2014; 3(6):1815-8.

[36] Jatkar KH, Dhanwe SS. Finite element analysis of gate valve. International Journal of Engineering and Innovative Technology. 2013; 2:277-81.

[37] Pujari AA, Joshi GS. Analysis and design optimization of 8"-600\# gate valve body using FEA and stress analysis. International Journal of Research in Engineering and Technology. 2016; 4(2):440-3.

[38] Mantati S, Surde AN. Finite element analysis of flexible wedge type (2"\#150) gate valve. International Journal of Emerging Technology and Advanced Engineering. 2015; 5(6):194-8.

[39] Sathishkumar S, Kannan M, Amirthalingam P, Arunkumar S, Natesh NS. Material development for thermo mechanical strained structural application. International Journal of Mechanical Engineering and Technology. 2016; 7(6):236-44.

[40] https://webstore.ansi.org/previewpages/MSS/preview_MSS+SP-91-2009.pdf. Accessed 23 November 2021.

[41] Jackson AS, Osburn HG, Laughery KR, Vaubel KP. Validity of isometric strength tests for predicting the capacity to crack, open, and close industrial valves. In proceedings of the human factors society annual meeting 1992 (pp. 688-91). Sage CA: Los Angeles, CA: SAGE Publications.

[42] Beckerle P, Schaede H, Rinderknecht S. Fault diagnosis and state detection in centrifugal pumps-a review of applications. In proceedings of the 9th IFToMM international conference on rotor dynamics 2015 (pp. 387-98). Springer, Cham.

[43] Chen Z, Liu T, Li J. The effect of the O-ring on the end face deformation of mechanical seals based on numerical simulation. Tribology International. 2016; 97:278-87.

[44] Xie F, Li Y, Ma Y, Xia S, Ren J. Cooling behaviors of a novel flow channel in mechanical seals of extreme high-speed rotation for cryogenic rockets. Cryogenics. 2020.

[45] Wang X, Liu M, Kao-walter S, Hu X. Numerical evaluation of rotordynamic coefficients for compliant foil gas seal. Applied Sciences. 2020; 10(11):1-9.

[46] Mosavat M, Moradi R, Takami MR, Gerdroodbary MB, Ganji DD. Heat transfer study of mechanical face seal and fin by analytical method. Engineering Science and Technology, an International Journal. 2018; 21(3):380-8

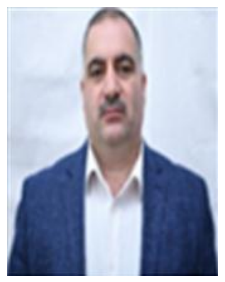

J. N. Aslanov was born in 1972 in Azerbaijan. He is Doctor of Philosophy in Technology in the field of oil and gas (mechanical engineering) at Azerbaijan State Oil and Industry University. His research interests are related to increase the efficiency of valves being used in industry $\mathrm{He}$ has got patents for 6 straight valves, 1 adjustable throttle, 1 plug valve and he is the author of 2 monographs, 2 textbooks, 2 manuals, 1 methodical instruction. He has several manuscripts, articles, thesis printed in international journals.

Email: tribo72@mail.ru

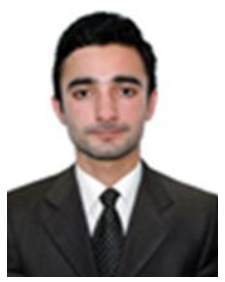

K. S. Mammadov is a Ph.D. student in the field of oil and gas (mechanical engineering) at Azerbaijan State Oil and Industry University since 2017. His research interests are related to increase the efficiency of valves being used in industry. He has several manuscripts, articles, thesis printed in international and national journals.

Email: khalig.mammadov1993@gmail.com

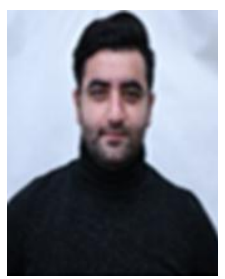

N. A. Zeynalov is a Ph.D. student in the field of oil and gas (mechanical engineering) at Azerbaijan State Oil and Industry University since 2017. His research interests are related to increase the reliability of valves being used in industry. He is the author of 3 articles and 2 thesis which are published in international and national journals.

Email: niyaz.zeynalov@asoiu.edu.az

Appendix I

\begin{tabular}{lll}
\hline S. No. & Abbreviation & Description \\
\hline 1 & FEA & Finite Element Analysis \\
\hline 2 & GOST & Government of the Soviet Union \\
\hline 3 & HB & Hardness Per Brinell \\
\hline 4 & MMW-1 & Type of Tribological Rig \\
\hline 5 & MPa & Mega Pascal \\
\hline 6 & N & Newton \\
\hline 7 & RT & Room Temperature \\
\hline 8 & s & Second \\
\hline 9 & ST & Steel \\
\hline
\end{tabular}

